Filol. linguist. port., n. 14(1), p. 73-97 2012.

\title{
A articulaçáo discursiva do gênero artigo de opinião à luz de um modelo modular de análise do discurso
}

Gustavo Ximenes Cunha ${ }^{1}$

\begin{abstract}
Resumo: Este artigo busca compreender as operações de construção discursiva de um gênero específico, o artigo de opinião. Com base no Modelo de Análise Modular do Discurso, mostramos que, na tentativa de convencer o leitor sobre um determinado ponto de vista, o autor de um artigo é levado a realizar diferentes manobras linguageiras, que se refletem na forma como as porções do discurso se articulam hierarquicamente, uma porção assumindo diversas funções em relação à outra, como as funções de argumento, preparação, comentário etc. Para isso, descrevemos as relações que os constituintes de um artigo específico estabelecem entre si, abordando, inicialmente, como o autor organiza as porções maiores do discurso e, em seguida, como essa organização se dá no interior dessas porções. O estudo permitiu verificar que, embora o gênero artigo de opinião seja monologal, o processo de sua produção implica o diálogo constante com o outro, o que tem como consequência a grande complexidade de sua organização discursiva.
\end{abstract}

Palavras-chave: Articulação Discursiva; Artigo de Opinião; Gênero; Modularidade.

\section{INTRODUÇÃO}

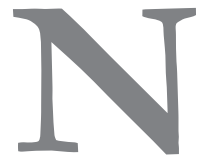

as últimas décadas, diferentes abordagens (Anscombre; Ducrot, 1983, Matthiessen; Thompson, 1988, Asher; Vieu, 2005) propuseram modelos para o estudo da articulação dos constituintes textuais que ultrapassam o limite do período ou oração complexa, limite a que se reduz a gramática tradicional. Essas abordagens, fornecendo ferramentas de análise com que estudar a macrossintaxe do discurso, se filiam à corrente mais ampla dos estudos pragmáticos, porque, de modo geral, investigam as manobras discursivas que o usuário da língua realiza ao construir o discurso

1 Doutorando em Linguística pela UFMG e bolsista do CNPq. E-mail: ximenescunha@ yahoo.com.br. 
oral ou escrito, na tentativa de alcançar determinado fim junto ao interlocutor. Assim, ao encadear atos de fala por meio de conectores argumentativos (Anscombre e Ducrot), desenvolver partes do discurso por meio de elaborações (Matthiessen e Thompson) ou narrar os sucessivos acontecimentos de uma história (Asher e Vieu), o que o produtor de um discurso busca é agir sobre o outro, convencendo-o, informando-o ou entretendo-o. Daí a importância dessas abordagens, que têm como finalidade geral explicitar, por meio de aparato teórico e técnico muitas vezes sofisticado, essas operações de construção discursiva.

Neste trabalho, o objetivo é mostrar como o arcabouço teórico de uma abordagem que compartilha dessa finalidade geral, o Modelo de Análise Modular do Discurso, pode ser utilizado de maneira satisfatória na compreensão das operações de construção discursiva de um gênero específico, o artigo de opinião. Além da importância concedida a esse gênero em diferentes veículos de comunicação, o artigo de opinião vem ganhando um espaço cada vez maior em materiais didáticos de língua portuguesa e em exames vestibulares, tendo em vista a complexidade das operações linguístico-discursivas que o autor é levado a mobilizar na tarefa de defender consistentemente um ponto de vista. Considerando a importância desse gênero em diferentes esferas, como a jornalística e a escolar, bem como a sua complexidade inerente, este trabalho busca evidenciar que essa complexidade vai além dos mecanismos microlinguísticos de superfície.

$\mathrm{Na}$ tentativa de convencer o leitor sobre um determinado ponto de vista, o autor de um artigo realiza diferentes manobras linguageiras, que se refletem na forma como as porções discursivas se articulam hierarquicamente, uma porção assumindo diversas funções em relação à outra, como as de argumento, preparação, comentário etc. Porque a articulação dessas porções no artigo de opinião costuma ser bastante complexa, torna-se relevante verificar como um modelo teórico como o que aqui nos orienta permite ao analista explicitar a articulação discursiva de um exemplar desse gênero, ultrapassando, ao mesmo tempo, o reducionismo da abordagem gramatical tradicional e o impressionismo de algumas abordagens do discurso, que se limitam a uma interpretação do conteúdo.

Para perseguir esse objetivo, apresentamos, inicialmente, o gênero artigo de opinião. Nessa apresentação, abordaremos algumas de suas propriedades situacionais mais características (interactantes, visadas, temática), expondo a forma como esse gênero estrutura o espaço social em que se dá a interação 
entre autor e leitor. Em seguida, apresentaremos o Modelo de Análise Modular do Discurso, explicitando os instrumentos que oferece para a análise da articulação discursiva. Por fim, realizaremos o estudo de um exemplar do gênero artigo de opinião, a fim de evidenciar como a complexidade de sua articulação resulta das manobras operadas pelo autor na tentativa de convencer o leitor.

\section{O GÊNERO ARTIGO DE OPINIÃO}

Integrante da esfera jornalística, o artigo de opinião é um gênero do discurso que se caracteriza por uma visada marcadamente comentativa, ocupando, no contínuo de gêneros elaborado por Adam (1997), o polo extremo do comentário, em oposição aos gêneros do polo extremo da informação, como a notícia, por exemplo. Oposição semelhante é esboçada por Charaudeau (2006), quando coloca o que chama de tribuna de opinião como um gênero que se opõe à reportagem por apresentar um especialista externo à instância midiática comentando um fato ou mesmo provocando a sua emergência.

Nesse sentido, a situação de interação que se materializa por meio do artigo de opinião engaja dois agentes, autor e leitor, os quais, no entanto, assumem posições ou status sociais diferentes e assimétricos. Nessa interação, o autor assume o status de autoridade em dado assunto, de figura de prestígio no espaço social, cujo saber é endossado e validado pela instituição (política, jornalística, industrial, acadêmica) que representa. Como observa Rodrigues (2005: 172), "O reconhecimento social e profissional do articulista outorga credibilidade a sua fala, alçando-o à posição de 'articulador' de um ponto de vista autorizado, de formador de opinião".

No diálogo com essa figura, o status que se reserva de forma esquemática para o leitor é o de cidadão geralmente integrante da classe média, que busca no autor a interpretação, a análise de um fato ocorrido no espaço social. Por esse motivo, o gênero artigo de opinião desenha uma relação dialógica assimétrica entre alguém que está institucionalmente autorizado a emitir o seu ponto de vista, o autor, e alguém que, desprovido dessa chancela institucional, busca um conhecimento, uma análise supostamente mais esclarecida, o leitor.

Nessa interação, o universo temático é preenchido por fatos recentemente ocorridos na esfera social, os quais, dada essa recência, interferem na vida do cidadão de modo geral e colocam parcelas da população em posições 
divergentes e antagônicas. Em outros termos, o universo temático do gênero artigo de opinião é povoado por fatos atuais e polêmicos. Por essa razão, autor e leitor dialogam sobre um “já-dito” (Rodrigues, 2005), sobre um fato que, após ter sido abordado pelo noticiário, mobilizou a atenção da opinião pública e agora pede que os veículos de comunicação apresentem as análises "esclarecidas" de especialistas da área em que o fato se deu.

Dada a natureza polêmica do fato a comentar, propiciando a manifestação de opiniões divergentes, mas igualmente esclarecidas em diferentes veículos, a relação assimétrica entre autor e leitor não garante a adesão deste às proposições defendidas no artigo. A incerteza quanto ao efeito alcançado junto ao leitor é a responsável pela dimensão argumentativa do gênero artigo de opinião. Embora a credibilidade do autor esteja pressuposta e não precise ser construída por meio de sua performance discursiva, o autor não pode se limitar a simplesmente explicitar o seu ponto de vista. Mais do que isso, o autor precisa buscar modificar a visão de mundo do leitor, convencendo-o da consistência de suas opiniões, dado o diálogo implícito ou explícito que mantém com opiniões adversárias.

Dessa "disputa" pelo leitor decorre o emprego, nos exemplares desse gênero, de um conjunto de recursos microlinguísticos especializados na busca por direcionar a interpretação, tais como conectores, operadores, modalizadores, desinências verbais e pronomes de $1^{\underline{a}}$ pessoa etc. Como marcas de superfície, esses recursos são importantes, porque sinalizam as diferentes manobras que o autor realiza ao articular as porções discursivas que compõem o artigo, manobras que exercem papel fundamental nas estratégias de defesa de um dado ponto de vista.

No próximo item, apresentaremos o Modelo de Análise Modular do Discurso, modelo cujos instrumentos de análise nos permitirão, no item 3, compreender a importância dessas manobras discursivas para a construção de um artigo de opinião.

\section{MODELO DE ANÁLISE MODULAR DO DISCURSO}

Em sua versão atual (Roulet; Filliettaz; Grobet, 2001, Filliettaz; Roulet 2002, Marinho; Pires; Villela, 2007), o modelo modular constitui um instrumento de análise que integra e articula, em uma perspectiva cognitivo- 
-interacionista, as dimensões linguística, textual e situacional da organização do discurso.

Compreendendo o discurso como um objeto cuja organização e cujo funcionamento envolvem aspectos de diferentes dimensões, Roulet (Roulet; Filliettaz; Grobet, 2001) levanta a hipótese de que é possível descrever o sistema da língua independentemente da situação de interação em que ela é utilizada, assim como é possível descrever as estruturas sintáticas de um discurso sem fazer referência à sua estrutura conceitual subjacente. Descritas de modo independente as informações que participam da organização do discurso, o modelo modular postula ainda que essas informações podem ser combinadas, a fim de se descreverem os diferentes aspectos envolvidos na produção e na interpretação dessa organização complexa que é o discurso.

Conforme a metodologia adotada pelo modelo modular, identificam-se inicialmente os módulos que entram na composição do discurso. ${ }^{2}$ Posteriormente, procura-se mostrar como as informações resultantes do estudo dos módulos se combinam em formas de organização do discurso. ${ }^{3}$

No modelo, o estudo das manobras discursivas realizadas por meio da articulação dos constituintes textuais se faz na forma de organização relacional. ${ }^{4}$ Como a base do estudo dessa forma de organização são as informações sobre a estrutura hierárquica do texto, o próximo subitem trata do módulo hierárquico,

2 Nessa abordagem, cada dimensão do discurso se constitui de módulos. Assim, a dimensão linguística se constitui dos módulos lexical e sintático; a dimensão textual se constitui do modulo hierárquico; e a dimensão situacional se constitui dos módulos interacional e referencial.

3 No modelo modular, distinguem-se dois tipos de formas de organização: as elementares e as complexas. As formas de organização elementares (fono-prosódica, semântica, relacional, informacional, enunciativa, sequencial e operacional) resultam da combinação ou acoplagem de informações extraídas dos módulos. Já as formas de organização complexas (periódica, tópica, polifônica, composicional e estratégica) resultam da combinação ou acoplagem de informações extraídas dos módulos e das formas de organização elementares e/ ou complexas.

4 O emprego de termos como constituintes textuais e relações discursivas remete aos conceitos de texto e discurso, os quais, no modelo modular, não são sinônimos. Para o modelo, o texto diz respeito à forma como os constituintes textuais (trocas, intervenções e atos) se organizam hierarquicamente, ao passo que o discurso constitui o ponto de interseção das dimensões linguística, textual e situacional. Nesse sentido, o texto constitui uma dimensão específica do discurso (Roulet; Filliettaz; Grobet, 2001, Cunha, 2010). 
que se ocupa da descrição dessa estrutura. Em seguida, as informações desse módulo serão combinadas com informações dos outros módulos no estudo da forma de organização relacional.

\subsection{Módulo hierárquico}

Nesse módulo, considera-se que "toda intervenção linguageira (cumprimento, pedido, asserção etc) constitui uma PROPOSIÇÃO, que desencadeia um processo de negociação entre os interactantes" (Roulet; Filliettaz; Grobet, 2001: 57). Assim, um diálogo formado por uma pergunta (Que horas são?), por uma resposta (São nove horas.) e por um agradecimento (Obrigado.) evidencia um processo em que uma proposição (a pergunta) desencadeia uma reação (a resposta), que motiva uma ratificação (o agradecimento).

Entretanto, nas interações efetivamente realizadas, as fases desse processo de negociação (proposição, reação, ratificação) assumem configurações complexas, raramente se reduzindo à intervenção de um único ato. Na interação mediada por discurso oral, a pergunta de um entrevistador, por exemplo, pode levar o entrevistado a manifestar-se por meio de um turno complexo formado de vários atos. Da mesma forma, na interação mediada por discurso escrito, uma reportagem composta de muitos atos constitui uma proposição, que pode levar o leitor a reagir por meio de uma carta endereçada ao jornalista, também composta de muitos atos (Cunha, 2008). Esses exemplos apontam para o fato de que a negociação conjunta dos interactantes costuma levar à construção de unidades discursivas complexas. Assim, a toda unidade textual subjaz um processo de negociação complexo, e é esse processo que as estruturas geradas no módulo hierárquico buscam reconstruir e tornar visíveis.

As estruturas hierárquicas são formadas pelos três tipos de constituintes que os interactantes produzem em toda interação verbal: trocas, intervenções e atos.

(1) Troca: unidade textual máxima, que é formada por intervenções que refletem as várias proposições, reações e ratificações de uma negociação.

(2) Intervenção: unidade constitutiva da troca, que pode ser formada por apenas um ato, mas que costuma apresentar uma configuração complexa, da qual participam outras intervenções, atos e até mesmo trocas. 
(3) Ato: unidade textual mínima, que constitui a menor unidade delimitada por uma e outra passagem da memória discursiva ${ }^{5}$.

Com a estrutura hierárquica, descrevem-se as hierarquias e as relações que os constituintes do texto - trocas, intervenções e atos - estabelecem entre si. Essas relações são de três tipos: dependência, interdependência e independência. Existe uma relação de dependência entre dois constituintes, quando a presença de um deles está ligada à presença do outro, ou seja, quando a presença de um depende da presença do outro. O constituinte dependente é chamado de subordinado e pode ser suprimido sem comprometer a estrutura global do texto; o outro constituinte é chamado de principal e exprime uma informação necessária para o texto. Existe uma relação de interdependência entre dois constituintes, quando um deles não pode existir sem o outro. Exemplifica a relação de interdependência uma troca formada por pergunta e resposta, já que a resposta depende da pergunta e vice-versa (Marinho, 2004). Finalmente, existe uma relação de independência, quando a presença de um constituinte não está ligada à presença de outro, isto é, quando a presença de um não depende da presença de outro. Exemplos desse tipo de relação são as intervenções ou os atos coordenados.

É importante frisar que, no modelo, a subordinação e a coordenação de constituintes textuais são fenômenos discursivos, fundamentalmente ligados à interação. Assim, o que define se um constituinte do texto é principal, subordinado ou coordenado em relação a outro constituinte é a sua importância para o desenvolvimento do processo de negociação entre os interactantes e não o elo sintático entre esses constituintes (Roulet; Filliettaz; Grobet, 2001, Cunha, 2011).

Neste trabalho, analisa-se o gênero artigo de opinião. As produções discursivas pertencentes a esse gênero não se configuram explicitamente como dialogais, porque não são produzidos por dois interactantes. Para o modelo, os discursos dessa natureza, isto é, os monologais correspondem a uma das fases

5 A memória discursiva é definida como "conjunto de saberes conscientemente partilhados pelos interlocutores" (Berrendonner, 1983: 230). Ela compreende "os diversos pré-requisitos culturais (normas comunicativas, lugares argumentativos, saberes enciclopédicos comuns etc) que servem de axiomas aos interlocutores para conduzir uma atividade dedutiva", bem como "as enunciações sucessivas que constituem o discurso" (Roulet; Filliettaz; Grobet, 2001: 23). 
do processo de negociação entre autor e leitor. Dessa forma, um artigo pode ser compreendido como uma intervenção que corresponde à fase intermediária de um processo de negociação - a reação. Isso porque a escrita de um artigo de opinião é motivada por um fato acontecido na esfera pública, fato que, em relação ao artigo, constitui uma proposição.

Cada uma das fases desse processo de negociação (proposição, reação, ratificação) pode ser analisada como uma intervenção complexa, já que a busca por defender um determinado ponto de vista, por exemplo, pode levar o autor a produzir uma intervenção formada por outras intervenções, as quais, por sua vez, são formadas por uma nova intervenção seguida de outra intervenção ou de um ato etc.

Como veremos a seguir, o estudo do modo como os constituintes textuais se estruturam hierarquicamente é a base da forma de organização relacional.

\subsection{Forma de organização relacional}

Nessa forma de organização, as informações do módulo hierárquico são combinadas com informações dos módulos lexical, sintático e referencial. O estudo dessa forma de organização se faz em duas etapas. Na primeira, identificam-se as relações ilocucionárias e interativas genéricas entre os constituintes da estrutura hierárquica e informações da memória discursiva. $\mathrm{Na}$ segunda etapa, determina-se a relação específica entre um constituinte em particular e uma informação da memória discursiva.

Na primeira etapa, a identificação das relações ilocucionárias e interativas genéricas se baseia em uma lista reduzida de categorias, as quais são consideradas suficientes para descrever todas as formas de discurso, tanto dialogal como monologal. Ao se utilizar dessas categorias, o modelo evita estabelecer a priori uma quantidade excessiva das relações específicas que podem ser encontradas em um discurso e consegue extrair generalizações importantes relativas à sua organização (Roulet, 2002, 2003). Com essas categorias de relações genéricas, é possível extrair o que Roulet (2002) chama de "o perfil relacional de um discurso", em que se evidenciam as relações dominantes de sua organização. A noção de argumento, por exemplo, é utilizada como categoria genérica para 
A articulação discursiva do gênero artigo de opinião à luz de um modelo modular de análise...

recobrir as relações interativas específicas de causa, explicação, justificação, argumento potencial etc.

As categorias de relações genéricas podem ser explicitadas por marcadores linguísticos, como os conectores e as construções sintáticas. Assim, a relação interativa de contra-argumento pode ser marcada por conectores, como mas, porém, embora etc. Da mesma forma, a relação ilocucionária de pedido pode ser marcada por uma construção sintática imperativa.

$\mathrm{Na}$ forma de organização relacional, as relações ilocucionárias caracterizam as intervenções que constituem as trocas. Essas relações podem ser iniciativas ou reativas, dependendo do lugar em que ocorre a intervenção na estrutura hierárquica. ${ }^{6}$ Distinguem-se três categorias genéricas de relações ilocucionárias iniciativas (interrogação, pedido e informação) e duas categorias genéricas de relações ilocucionárias reativas (resposta e ratificação) (Roulet; Filliettaz; Grobet, 2001). Diferentemente do que se postula na Teoria dos Atos de Fala, as relações ilocucionárias iniciativas e reativas no modelo modular não caracterizam atos isolados, mas as intervenções constitutivas das trocas, intervenções que, como apontado na descrição do módulo hierárquico, podem assumir configurações complexas.

As relações interativas, por sua vez, caracterizam os constituintes das intervenções. Distinguem-se oito categorias genéricas de relações interativas: argumento, contra-argumento, reformulação, topicalização, sucessão, preparação, comentário e clarificação. O estabelecimento das categorias genéricas de relações interativas se justifica pelo fato de que o agente, na tentativa de alcançar seus objetivos comunicativos, pode produzir intervenções complexas. Nessas intervenções, ele pode introduzir argumentos para reforçar um ponto de vista, rejeitar uma ideia com a apresentação de contra-argumentos, comentar partes de seu texto, reformular ideias, tornando-as mais claras para seu ouvinte/leitor, enumerar os sucessivos eventos de uma narração etc (Roulet, 2006).

Como foi dito, o estudo das relações de discurso genéricas constitui a primeira etapa da análise da forma de organização relacional. Aprofundando

6 "A primeira intervenção de uma troca é ligada à segunda por uma relação ilocucionária iniciativa; a última intervenção de uma troca é ligada à precedente por uma relação ilocucionária reativa; e cada intervenção intermediária é ligada à precedente por uma relação ilocucionária reativa e à próxima por uma relação ilocucionária iniciativa” (Roulet, 2006: 120). 
esse estudo, a segunda etapa descreve as relações ilocucionárias e interativas específicas entre um constituinte textual e uma informação da memória discursiva. Essa descrição é importante, porque permite distinguir, por exemplo, as relações de argumento marcadas por conectores daquelas que não apresentam nenhuma marcação linguística ou uma relação de argumento marcada por porque de relações que são marcadas por pois, portanto, aliás etc (Roulet; Filliettaz; Grobet, 2001).

$\mathrm{Na}$ análise relacional, o estudo das especificidades de cada relação discursiva é feito com a aplicação de um cálculo inferencial, que se baseia nas propriedades linguísticas, hierárquicas e referenciais dos constituintes do texto. Para realizar esse cálculo, formulam-se premissas com base nas informações linguísticas dos constituintes textuais. Nessas premissas, as informa ções linguísticas são enriquecidas pelos referentes que saturam pronomes, expressões nominais e desinências verbais, como as instâncias agentivas que participam da interação e demais elementos dêiticos. Caso a relação seja marcada por conector, formula-se, em seguida, outra premissa a partir da instrução (gramatical ou pragmática) desse conector. Finalmente, com base nessas premissas, chega-se à conclusão ou interpretação final sobre a relação específica considerada (Marinho, 2002, Roulet, 2003).

A seguir; verificaremos como o conjunto de instrumentos de análise aqui exposto (esquema de negociação, estrutura hierárquica, relações de discurso genéricas e específicas) possibilita uma análise precisa e detalhada das manobras discursivas que o autor de um artigo de opinião realiza na busca por convencer o leitor. Seguindo a metodologia proposta pelo modelo modular, estudaremos, inicialmente, as relações discursivas genéricas e, depois, as relações discursivas específicas entre os constituintes textuais desse artigo.

\section{ANÁLISE DA FORMA DE ORGANIZAÇÃO RELACIONAL DE UM EXEMPLAR DO GÊNERO ARTIGO DE OPINIÃO}

\subsection{Relações discursivas genéricas}

O artigo de opinião escolhido para este trabalho constitui uma intervenção, cujos constituintes se articulam de forma bastante complexa. Escrito por Gilberto Dimenstein, jornalista de prestígio em sua esfera de atuação, e 
publicado na versão online do jornal "Folha de S. Paulo", o artigo intitulado "É um crime" constitui uma reação à notícia veiculada na própria Folha, em 05/07/2011, sobre o resultado dos alunos no Exame da Ordem dos Advogados do Brasil (OAB). De acordo com a notícia:

A OAB (Ordem dos Advogados do Brasil) divulgou nesta terça-feira uma lista com as 90 faculdades que não aprovaram nenhum aluno na última edição do Exame da Ordem. A lista deve ser encaminhada ao Ministério da Educação. ${ }^{7}$

Reagindo a essa notícia, o jornalista escreve o artigo transcrito a seguir: ${ }^{8}$ (01) É um crime

(02) A divulgação da lista das faculdades que não aprovaram nenhum aluno no exame da OAB é apenas o lado ainda mais escandaloso de um escândalo: (03) jovens passam anos pagando mensalidades (04) (em geral vindos de famílias mais pobres) (05) e, no final, têm de jogar o diploma fora. (06) Deveria ser um crime contra o direito do consumidor.

(07) O escândalo maior é que a maioria não passa, (08) cerca de $90 \%$ dos candidatos. (09) O que revela um drama educacional geral, (10) desde o ensino básico, (11) agravando-se na faculdade. (12) É gente que sequer sabe ler um texto direito. (13) Muitas faculdades são obrigadas a dar aulas de português.

(14) O escândalo poderia ser ainda maior (15) se todas as profissões exigissem semelhante exame ao do OAB. (16) Os poucos que existem - medicina, por exemplo - já são uma tragédia.

(17) Difícil ver maior crime educacional do que tirar durante anos dinheiro dos alunos das classes mais pobres (18) e transformá-lo em lixo (19) exceto, claro, para os donos das faculdades.'

Como se vê, a notícia e o artigo materializam um processo de negociação, já que a proposição (notícia) é seguida por uma reação (artigo).

7 Disponível em: <http://www1.folha.uol.com.br/saber/939159-oab-divulga-90-faculdades-sem-aprovados-em-exame-veja.shtml>. Acesso em: 11/07/2011.

8 A numeração indica que o texto foi segmentado em atos. Para uma apresentação sobre os critérios de segmentação de um discurso em atos, ver Grobet (2000: 77-96), Roulet, Fillietaz e Grobet (2001: 58-71) e Marinho (2007).

9 Disponível em: <http://www1.folha.uol.com.br/colunas/gilbertodimenstein/939263-e-um-crime.shtml>. Acesso em: 11/07/2011. 
Esse processo de negociação pode ser representado por meio de uma estrutura de troca: ${ }^{10}$

$\mathrm{T}\left[\begin{array}{l}\text { I (notícia) } \\ \text { In } \\ \text { I (artigo de opinião) }\end{array}\right.$

Re

FIGURA 1: Troca notícia e artigo

A articulação dos dois discursos nessa estrutura evidencia a ligação do artigo com o "já-dito" que motivou a sua escrita. Em outros termos, a troca representa o diálogo entre um jornalista que apresenta um fato recente e uma voz institucionalmente autorizada, o articulista, que realiza a análise desse fato. No nível das relações ilocucionárias, enquanto a primeira intervenção (a notícia) se liga à segunda por uma relação iniciativa de informação, a segunda intervenção (o artigo) se liga à primeira por uma relação reativa de resposta. Nesse sentido, a reação de Gilberto Dimenstein constitui uma resposta ao problema colocado pelo jornalista na notícia.

Na sequência, será descrito o modo como o articulista realiza a forma de organização relacional do artigo de opinião. Essa descrição será feita do nível macrotextual para o nível microtextual, abordando, inicialmente, como o autor organiza as porções maiores do artigo e, em seguida, como essa organização se dá no interior dessas porções.

A figura abaixo apresenta a macroestrutura hierárquico-relacional do artigo de opinião, que tem por função representar a articulação textual do artigo em nível global: ${ }^{11}$

10 Troca $=\mathrm{T}$; intervenção $=\mathrm{I}$; iniciativa $=\mathrm{In}$; reativa $=$ Re.

11 Informações hierárquicas: ato principal $=A$ p, ato subordinado $=A$ s, intervenção principal $=\mathrm{I}$, intervenção subordinada $=$ Is. Informações relacionais: preparação $=$ prep, argumento $=$ arg, contra-argumento $=\mathrm{c}-\arg$. 


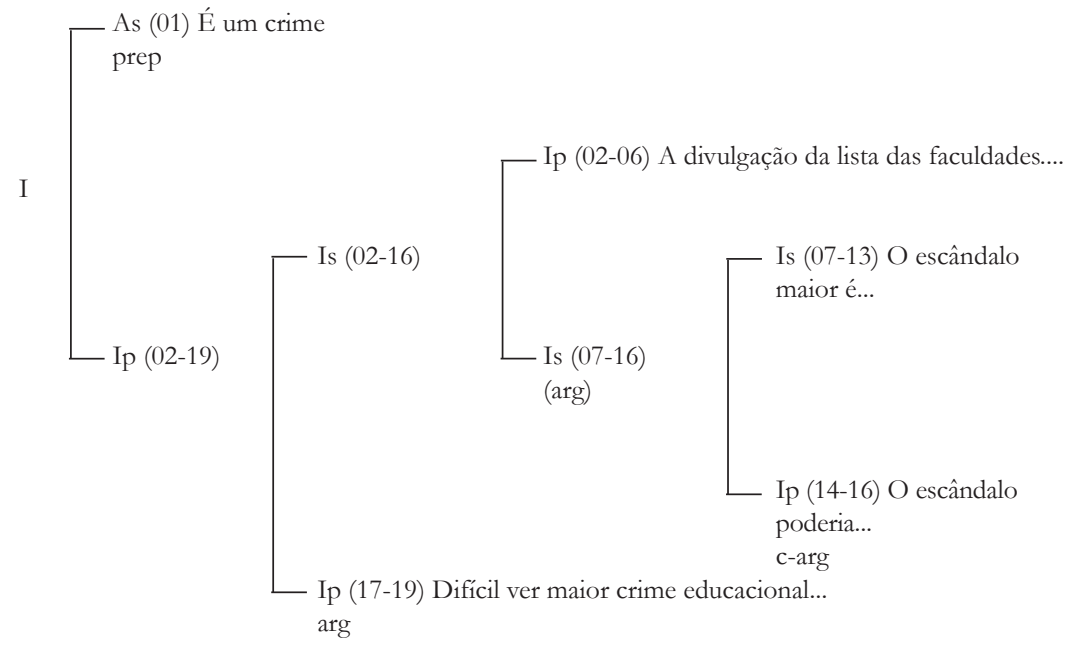

FIGURA 2: Macroestrutura hierárquico-relacional do artigo de opinião

Com o título "É um crime", o autor prepara o leitor para as informações da parte central do artigo, antecipando a natureza argumentativa e de denúncia de seu discurso. Por isso, o título é um ato subordinado em relação ao restante do artigo e se liga a ele por uma relação de preparação.

No primeiro parágrafo (Ip 02-06), o autor delimita o tema que será abordado (o resultado do exame da $\mathrm{OAB}$ ) e explicita seu ponto de vista, segundo o qual é um escândalo jovens passarem anos pagando mensalidades de algumas faculdades e, ao final, terem de jogar o diploma fora. Como o autor explicita o seu ponto de vista nesse parágrafo, este tem o estatuto de principal em relação aos dois parágrafos seguintes, os quais funcionam como argumentos para o autor defender que "deveria ser um crime o fato de jovens passarem anos pagando mensalidades e, ao final, jogarem fora o diploma".

No segundo parágrafo (Is 07-13), o autor trata de forma mais detalhada de um problema específico dos alunos que não passam no exame da $\mathrm{OAB}$, problema cuja origem está no ensino básico e que, por isso, antecede a entrada desses alunos na faculdade: "É gente que sequer sabe ler um texto direito. Muitas faculdades são obrigadas a dar aulas de português”.

$\mathrm{Na}$ busca por convencer o leitor da seriedade desse problema, o autor encadeia o terceiro parágrafo (Ip 14-16) nas informações expressas no segundo. 
As informações do segundo parágrafo podem ser parafraseadas da seguinte forma: "O escândalo maior é que a maioria dos alunos não passa no exame da $\mathrm{OAB}$, porque existe um drama educacional geral, que faz com que esses alunos não saibam sequer ler um texto direito". Com essas informações, o autor buscou no segundo parágrafo delinear um quadro educacional grave. Mas, no terceiro parágrafo, o autor intensifica a gravidade desse quadro, ao dizer: "(14) O escândalo poderia ser ainda maior (15) se todas as profissões exigissem semelhante exame ao do OAB.” Por isso, a intervenção formada por esse parágrafo funciona como um contra-argumento para as informações expressas no segundo. É como se o autor dissesse, com o terceiro parágrafo, que o problema é ainda maior do que o leitor imagina. Essa interpretação pode ser evidenciada por meio da inserção do conector mas no início desse parágrafo: "[Mas] (14) O escândalo poderia ser ainda maior (15) se todas as profissões exigissem semelhante exame ao do OAB".

Após defender o ponto de vista expresso no primeiro parágrafo por meio das informações apresentadas nos dois seguintes, o autor conclui o artigo com a Ip (17-19), qualificando como "crime educacional" a atitude das faculdades que não tiveram alunos aprovados no exame da OAB de tirar o dinheiro desses alunos, que, em geral, pertencem às classes mais pobres. Por meio dessa conclusão, o autor subordina, de forma retroativa, os três primeiros parágrafos, já que é dessa parte final que se pode extrair, de forma explícita, a opinião defendida pelo jornalista.

Ao revelar que as porções maiores do artigo se articulam por meio de relações de preparação, argumento e contra-argumento, essa análise evidencia as manobras linguageiras realizadas pelo autor no nível macroestrutural para convencer o leitor da pertinência de seu ponto de vista. No diálogo que estabelece com o leitor, o autor explicita, inicialmente, seu ponto de vista, sustenta, em seguida, esse ponto de vista por meio de argumentos e mostra-se, finalmente, insatisfeito com a situação contra a qual se coloca.

Feita a análise macroestrutural, passemos à análise de cada intervenção constituída pelos parágrafos, verificando as manobras linguageiras realizadas pelo autor no interior de cada grande intervenção. A estrutura hierárquico-relacional do primeiro parágrafo pode ser representada da seguinte forma: 


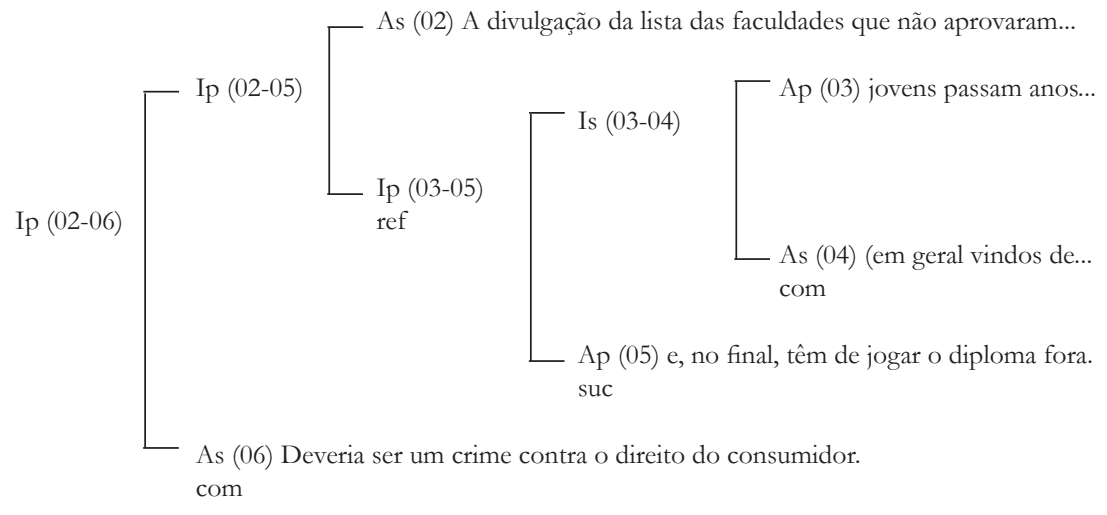

FIGURA 3: Estrutura hierárquico-relacional do primeiro parágrafo

No ato (02), o autor delimita o tema de que trata seu discurso ("A divulgação da lista das faculdades que não aprovaram nenhum aluno no exame da OAB”) e informa que esse tema constitui um problema: “é apenas o lado ainda mais escandaloso de um escândalo". Como esse ato anuncia um escândalo, ele é subordinado aos atos (03-05), em que o autor informa o problema em relação ao qual se posiciona: “(03) jovens passam anos pagando mensalidades (04) (em geral vindos de famílias mais pobres) (05) e, no final, têm de jogar o diploma fora”. Nesse sentido, os atos (03-05) reformulam a informação expressa em (02), tornando-a mais clara. Os dois-pontos com que o autor finaliza o ato (02) funcionam como um sinal de que as informações que conecta estabelecem uma relação de reformulação.

Na intervenção formada pelos atos (02-05), o (04) é um comentário do autor em relação a um objeto de discurso expresso em (03), jovens: “em geral, eles [os jovens] vêm de famílias mais pobres". Já o ato (05) subordina os atos (0304), porque expressa um fato posterior ao mencionado nesses atos (primeiro, os jovens vindos de famílias mais pobres passam anos pagando mensalidades (03-04) e, depois, têm de jogar o diploma fora (05)). Por fim, os atos (02-05) subordinam o (06), já que neste ato o articulista faz um comentário avaliativo em relação a tudo o que disse no parágrafo: o escândalo apresentado deveria ser um crime contra o direito do consumidor.

O segundo parágrafo tem a seguinte estrutura hierárquico-relacional: 


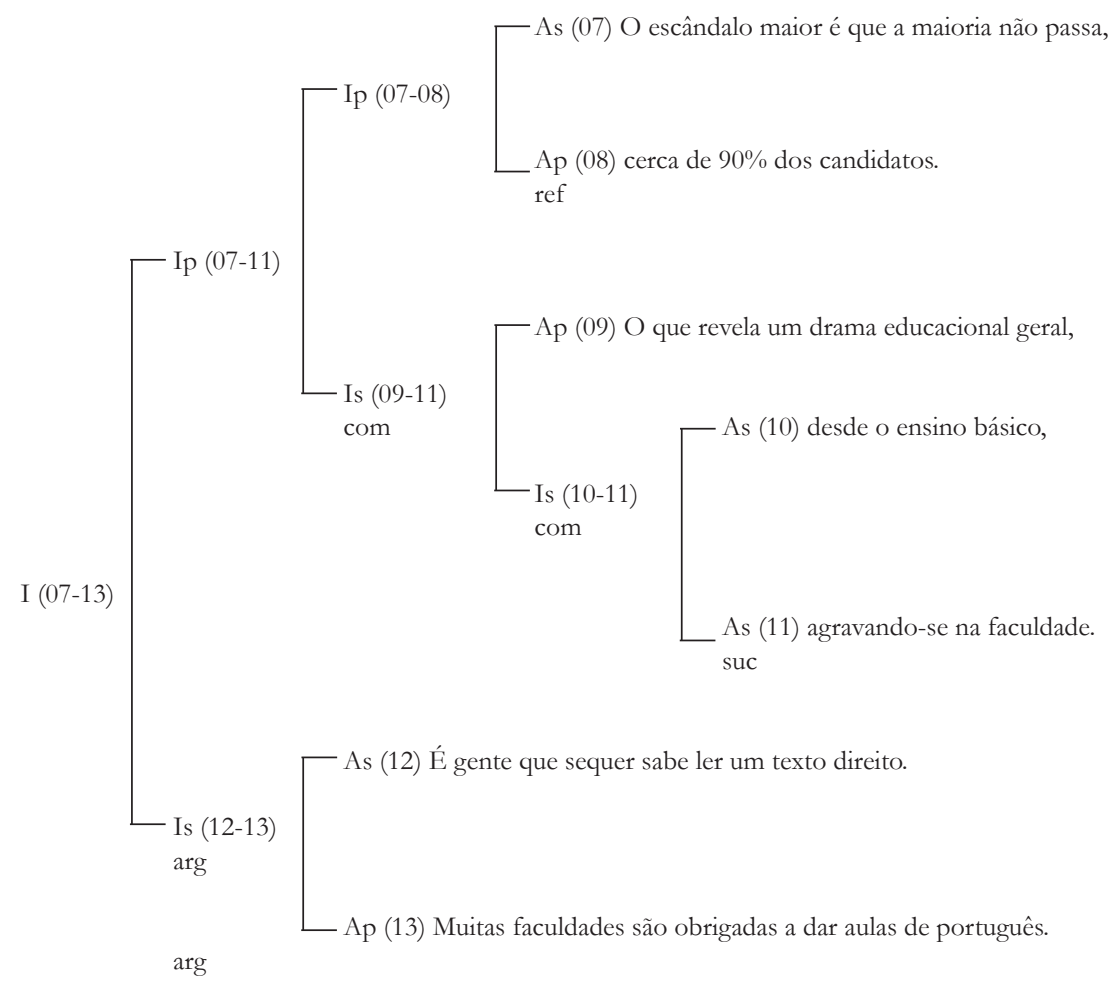

FIGURA 4: Estrutura hierárquico-relacional do segundo parágrafo

No ato (07), o autor se refere ao escândalo que constitui o fato de a maioria dos alunos não passarem no exame a OAB. No (08), ele esclarece, reformulando, o sentido da expressão a maioria presente no ato anterior: a maioria é formada por cerca de $90 \%$ dos candidatos. Por isso, o ato (08) é principal em relação ao (07). A intervenção formada por (07-08) subordina a intervenção formada pelos atos (09-11), em que o articulista faz um comentário referente ao histórico escolar desses alunos, histórico designado pela expressão drama educacional geral: “(09) O que revela um drama educacional geral, (10) desde o ensino básico, (11) agravando-se na faculdade".

É interessante observar que, embora constituindo, do ponto de vista sintático, uma oração subordinada, a intervenção (09-11) é separada da intervenção (07-08) por ponto final, formando o que Decat (2011) conceitua como 
oração desgarrada ${ }^{12}$. Essa opção parece ter sido motivada pela busca do autor de realçar as informações expressas nesse constituinte desgarrado, chamando a atenção do leitor para o comentário que veicula acerca dos atos (07-08), para o "drama educacional" revelado. Nesse sentido, o "desgarramento" de um constituinte pode ser visto como uma marca da relação de comentário.

Nesse constituinte desgarrado formado pelos atos (09-11), o (09) subordina (10-11), porque estes trazem informações suplementares ou um comentário sobre o começo e o fim do “drama educacional". Nessa intervenção subordinada formada por (10-11), o agravamento do drama na faculdade ocorre depois da passagem do aluno pelo ensino básico. Por isso, (10) se subordina a (11) por uma relação de sucessão temporal.

Acrescentando informações sobre a intervenção (07-11), o autor apresenta, em (12), características dos alunos reprovados ("É gente que sequer sabe ler um texto direito") e explica, em (13), a medida tomada por faculdades ("Muitas faculdades são obrigadas a dar aulas de português"). Por isso, os atos (12-13) funcionam como argumento que sustenta a opinião expressa pelo articulista de que há um drama educacional. Para ele, esse drama existe (atos 07-11), e uma prova disso é que os alunos de muitas faculdades não sabem sequer ler um texto direito (atos 12-13). A função argumentativa dos atos (1213) pode ser revelada, inserindo-se antes deles o conector porque: "O que revela um drama educacional geral, (10) desde o ensino básico, (11) agravando-se na faculdade. (12) [Porque] É gente que sequer sabe ler um texto direito. (13) Muitas faculdades são obrigadas a dar aulas de português".

No ato (12), o modalizador sequer tem um papel importante na emergência da função argumentativa da intervenção de que participa. Com esse modalizador, o autor revela que, para ele, é inadmissível alunos universitários não dominarem de forma satisfatória a habilidade de leitura. A importância do sequer pode ser percebida com a sua substituição pelo advérbio de negação não:

12 São considerados desgarrados ou soltos constituintes textuais, como sintagmas nominais ou orações apositivas, que "ocorrem livremente, sem estarem vinculados sintaticamente a nenhuma oração" (Decat, 2011: 83). Quanto à função desses constituintes desgarrados, esclarece Decat (2011: 87) que "A necessidade de reforçar um ponto de vista, de dar realce, ênfase a um determinado aspecto, leva o produtor do texto a fazer uso de sequências argumentativas, materializadas linguisticamente através da estratégia do 'desgarramento' de orações ou de SNs". 
"É gente que não sabe ler um texto direito". Essa substituição enfraquece o papel do ato (12) na construção de uma intervenção com função de argumento, porque diminui a convicção do autor em relação à informação que expressa. Dessa forma, o sequer, assim como outros modalizadores epistêmicos, revela o grau de certeza do autor quanto à sua afirmação. Ao utilizar esse modalizador, o autor do artigo "avalia como verdadeiro o conteúdo do enunciado que produz, apresentando-o como uma asseveração [...], sem espaço para dúvida e sem nenhuma relativização" (Neves, 2002: 188).

A estrutura hierárquico-relacional do terceiro parágrafo pode ser assim representada:

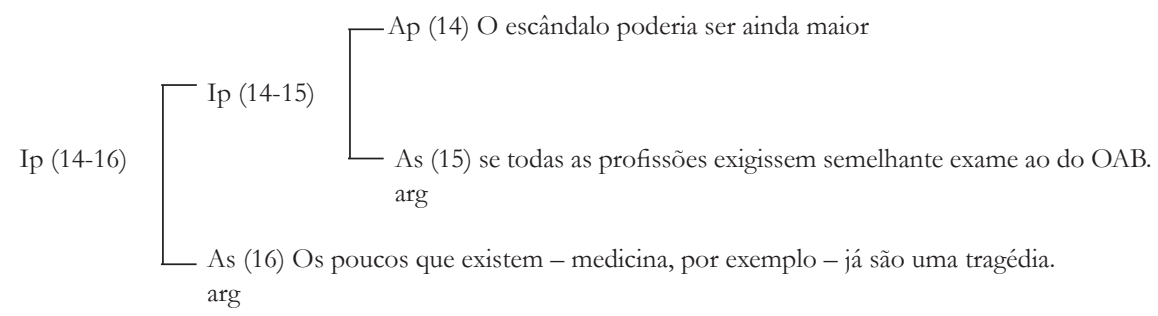

FIGURA 5: Estrutura hierárquico-relacional do terceiro parágrafo

Nessa intervenção, o autor defende que o problema dos alunos reprovados poderia ser maior (ato 14), se todas as profissões exigissem um exame semelhante ao da OAB (ato 15). Por isso, o ato (15) funciona como um argumento para sustentar a informação expressa em (14), o que é sinalizado pelo conector se. A natureza hipotética das informações contidas na intervenção (14-15) é sinalizada, em (14), pelo verbo no futuro do pretérito poderia e, em (15), pelo conector se e pelo verbo no subjuntivo exigissem. Mas, para mostrar que o que disse não é mera hipótese, o autor informa, em (16), que os "poucos que existem - medicina, por exemplo - já são uma tragédia". Por essa razão, o ato (16) atua como argumento, como uma prova de que a situação imaginada pelo autor em (14-15) faz sentido: "(14) O escândalo poderia ser ainda maior (15) se todas as profissões exigissem semelhante exame ao do OAB. (16) [Prova disso é que] Os poucos que existem - medicina, por exemplo - já são uma tragédia. 
Por fim, o último parágrafo apresenta a seguinte estrutura hierárquico-relacional:

$\operatorname{Ip}(17-19) \longleftarrow \begin{aligned} & \text { Ip (17-18) } \\ & \text { Ap (18) e transformá-lo em lixo } \\ & \text { suc } \\ & \text { As (19) - exceto, claro, para os donos das faculdades. }\end{aligned}$

FIGURA 6: Estrutura hierárquico-relacional do último parágrafo

Nesse parágrafo, o ato (18) se liga ao (17) por uma relação de sucessão, já que entre as informações expressas por esses atos há uma relação cronológica, que pode ser marcada por depois: “(17) Difícil ver maior crime educacional do que tirar durante anos dinheiro dos alunos das classes mais pobres (18) e [depois] transformá-lo em lixo". No ato (17), o autor redefine como crime educacional o que qualificara, em (09), apenas como drama educacional: "(09) O que revela um drama educacional geral". Para o autor, recategorizar drama como crime na parte final do artigo é importante, porque permite informar explicitamente, em (19), quem são, para ele, os responsáveis pelo problema: "os donos das faculdades". Ao mencionar, em (19), os donos das faculdades, o autor especifica quem é o agente do verbo tirar, mencionado em (17), isto é, ele informa quem tira "durante anos dinheiro dos alunos das classes mais pobres". É interessante observar que a menção aos donos das faculdades é feita em um ato, o (19), que se liga à intervenção anterior (17-18) por uma relação de contra-argumentação marcada pelo conector "exceto" e que é separado dessa intervenção por um travessão. Essa forma de introduzir o referente donos das faculdades ajuda a realçá-lo, intensificando a sua importância para a argumentação construída.

A análise da organização relacional genérica desse artigo forneceu uma descrição das relações interativas entre os seus constituintes e informações da memória discursiva, todas com origem no próprio artigo. Com essa descrição, foi possível extrair o "perfil relacional” do discurso (Roulet, 2002), em que se percebe o predomínio das relações de argumento, contra-argumento, comentá- 
rio e reformulação. O predomínio dessas relações revela um discurso altamente argumentativo, em que, para convencer o leitor de um dado ponto de vista, o autor se vale de diferentes e complexas manobras discursivas.

Realizada a análise das relações interativas genéricas, é possível estudar a seguir, na segunda etapa da forma de organização relacional, a relação específica que um constituinte textual estabelece com uma informação da memória discursiva.

\subsection{Relações discursivas específicas}

Por motivo de espaço, estudaremos apenas duas relações específicas, uma marcada e uma não marcada por conector. Ambas as relações articulam constituintes do terceiro parágrafo, reproduzido a seguir:

(14) O escândalo poderia ser ainda maior (15) se todas as profissões exigissem semelhante exame ao do OAB. (16) Os poucos que existem - medicina, por exemplo - já são uma tragédia.

Nesse parágrafo, a relação entre os atos (14-15) é marcada pelo conector se. O cálculo inferencial dessa relação pode ser esquematizado da seguinte maneira:

\section{QUADRO 1: Cálculo inferencial da relação entre (14-15)}

\begin{tabular}{|c|c|l|}
\hline Premissa 1 & $\begin{array}{c}\text { Informação linguística } \\
\text { enriquecida }\end{array}$ & $\begin{array}{l}\text { O autor afirma ao leitor que o escândalo dos } \\
\text { alunos do curso de Direito reprovados no } \\
\text { exame da OAB poderia ser maior do que já é. }\end{array}$ \\
\hline Premissa 2 & $\begin{array}{c}\text { Informação linguística } \\
\text { enriquecida }\end{array}$ & $\begin{array}{l}\text { O autor solicita ao leitor que imagine uma } \\
\text { situação em que todas as profissões exigem } \\
\text { um exame semelhante ao da OAB. }\end{array}$ \\
\hline Premissa 3 & $\begin{array}{c}\text { Informação lexical } \\
\text { (instrução do se) }\end{array}$ & $\begin{array}{l}\text { Utiliza-se o conector se para introduzir um } \\
\text { argumento potencial em relação à informação } \\
\text { expressa em outro constituinte. }\end{array}$ \\
\hline Conclusão & Interpretação & $\begin{array}{l}\text { O autor solicita ao leitor que imagine uma } \\
\text { situação em que todas as profissões exigem } \\
\text { um exame semelhante ao da OAB como um } \\
\text { argumento potencial para defender que o } \\
\text { escândalo dos alunos do curso de Direito } \\
\text { reprovados no exame da OAB poderia ser } \\
\text { maior do que já é. }\end{array}$ \\
\hline
\end{tabular}


Nesse cálculo, as premissas 1 e 2 recuperam as informações da memória discursiva necessárias para a compreensão dos atos (14-15), respectivamente. Na premissa 3, a informação lexical do se explicita a instrução básica que esse conector fornece ao leitor. Com base nessas premissas, a conclusão apresenta a interpretação resultante desse percurso inferencial, à qual se segue a definição da relação específica entre os atos: argumento potencial.

Com essa interpretação, evidencia-se a forma como o autor, em diálogo com o leitor, encadeia o ato (15) em uma informação da memória discursiva com origem em (14), fazendo de (15) um argumento potencial, o que é indicado pela instrução básica do conector se.

No parágrafo em análise, a relação entre a intervenção formada pelos atos (14-15) e o ato (16) não é marcada por nenhum conector. O cálculo dessa relação pode ser esquematizado da seguinte forma:

\section{QUADRO 2: 'álculo inferencial da relação entre (14-15) e (16)}

\begin{tabular}{|c|c|l|}
\hline Premissa 1 & $\begin{array}{c}\text { Informação linguística } \\
\text { enriquecida }\end{array}$ & $\begin{array}{l}\text { O autor defende que o escândalo dos alunos } \\
\text { do curso de Direito reprovados no exame } \\
\text { da OAB poderia ser maior do que já é, se } \\
\text { todas as profissões exigissem um exame } \\
\text { semelhante ao da OAB. }\end{array}$ \\
\hline Premissa 2 & $\begin{array}{c}\text { Informação linguística } \\
\text { enriquecida }\end{array}$ & $\begin{array}{l}\text { O autor afirma ao leitor que os poucos } \\
\text { exames que avaliam os alunos de outros } \\
\text { cursos - medicina, por exemplo - já são } \\
\text { uma tragédia. }\end{array}$ \\
\hline Conclusão & $\begin{array}{l}\text { O autor defende que o escândalo dos alunos } \\
\text { do curso de Direito reprovados no exame } \\
\text { da OAB poderia ser maior do que já é, se } \\
\text { todas as profissões exigissem um exame } \\
\text { semelhante ao da OAB. E, como prova disso, } \\
\text { afirma que os resultados dos poucos exames } \\
\text { que avaliam os alunos de outros cursos - } \\
\text { medicina, por exemplo - já são uma tragédia. }\end{array}$ \\
\hline
\end{tabular}

Nesse cálculo, a premissa 1 recupera as informações necessárias para a compreensão da intervenção (14-15), enquanto a premissa 2 enriquece com informações da memória discursiva o ato (16). Na conclusão, evidencia-se que o autor utiliza o ato (16) como uma prova para sustentar as informações 
expressas em (14-15). Porém, a prova apresentada em (16) é não-factual, já que o autor afirma que os resultados dos exames que avaliam outros cursos são uma tragédia, mas não apresenta nenhuma prova concreta (documentos, relatórios, dados de instituições educacionais) que ateste a veracidade do que diz. Por essa razão, a relação específica entre (14-15) e (16) é definida, ao final do cálculo, como sendo de prova não-factual.

A análise dessas duas relações específicas é importante por algumas razões. Em primeiro lugar, permite precisar o papel dos conectores na marcação de uma relação de discurso. Além do verbo no futuro do pretérito no ato (14) (poderia), o conector se funciona como uma instrução importante para o leitor perceber que a informação dada em (15) é hipotética, devendo ter a sua validade restringida. Por essa razão, o conector se funciona tipicamente como um introdutor de argumento potencial (Ducrot, 1977).

Em segundo lugar, essa análise permite verificar que, embora as duas relações estudadas pertençam à categoria genérica de argumento, elas apresentam diferenças consideráveis, das quais não se ocupa, no entanto, a primeira etapa da análise da forma de organização relacional. Assim, só avançando o estudo para esta segunda etapa, pudemos verificar que se trata de duas relações específicas distintas. Enquanto a primeira é uma relação de argumento potencial, a segunda é uma relação de argumento por prova não-factual.

\section{CONSIDERAÇÕES FINAIS}

Neste trabalho, buscamos evidenciar que a construção de um artigo de opinião é uma atividade complexa, que requer a realização de diferentes manobras discursivas. Dado o objetivo do articulista de "revelar" ao leitor um ponto de vista esclarecido acerca de um fato polêmico, ele não se limita a emitir sua opinião. Ao contrário, a tentativa de garantir a adesão do leitor às proposições defendidas leva o autor a realizar diferentes manobras, tais como argumentar, comentar, reformular, contra-argumentar, manobras que ocorrem tanto no nível macrodiscursivo quanto no nível microdicursivo.

Como consequência dessas manobras realizadas em diferentes níveis, o artigo de opinião é um gênero, cujos exemplares exibem uma organização bastante complexa. Apoiados no Modelo de Análise Modular do Discurso, 
buscamos compreender essa complexidade por meio da descrição da forma de organização relacional do artigo "É um crime”. Essa descrição permitiu observar que a construção de um artigo é complexa não só pela seleção de elementos microlinguísticos de superfície, como conectores e advérbios, mas também pela forma como as porções discursivas se relacionam hierarquicamente. No artigo analisado, a sua organização relacional exibe uma predominância de algumas relações, como as de argumento, contra-argumento, comentário e reformulação. A predominância dessas relações ou esse perfil relacional evidencia um autor empenhado em construir uma argumentação capaz de convencer o leitor de um dado ponto de vista.

Com este trabalho, esperamos contribuir para uma melhor compreensão dos gêneros do discurso, de modo geral, e do gênero artigo de opinião, em particular, ao apresentar uma proposta de análise que busca, ao mesmo tempo, ultrapassar a descrição gramatical tradicional e não se limitar a uma simples interpretação do conteúdo veiculado.

\section{BIBLIOGRAFIA}

ADAM, J-M. 1997. Unités rédactionnelles et genres discursifs: cadre général pour une approche de la presse écrite. Pratiques 94, p. 3-18.

ANSCOMBRE, J. C.; DUCROT, O. 1983. L'argumentation dans la langue. Liege - Bruxelles: Pierre Mardaga.

ASHER, N.; VIEU, L. 2005. Subordinating and coordinating discourse relations. Lingua. v. 115, p. 591-610.

BERRENDONER, A. 1983. "Connecteurs pragmatiques” et anaphore. Cabiers de linguistique française 5, p. 215-246.

CHARAUDEAU, P. 2006. Discurso das mídias. Trad. Angela M. S. Correa. São Paulo: Contexto.

CUNHA, G. X. 2008. O sequenciamento de textos como estratégia discursiva: uma abordagem modular. Dissertação (Mestrado em Linguística) - Faculdade de Letras, Universidade Federal de Minas Gerais, Belo Horizonte.

2010. A função de conectores argumentativos no texto da proposta curricular de Minas Gerais. Alfa: Revista de Linguística 54, p. 203-222.

. 2011. Análise do funcionamento atípico do conector quando como marca de reformulação. ReVEL 9. n. 17, p. 55-67. 
DECAT, M. B. N. 2011. Estruturas desgarradas em Lingua Portuguesa. Campinas: Pontes Editores.

DUCROT, O. 1977. Princípios de semântica linguística (dizer e não dizer). São Paulo: Cultrix.

FILLIET'TAZ, L.; ROULET, E. 2002. The Geneva Model of discourse analysis: an interactionist and modular approach to discourse organization. Discourse Studies 4(3), p. 369-392.

GROBET, A. 2000. L'identification des topiques dans les dialogues. Tese (Doutorado em Linguística) - Faculdade de Letras, Universidade de Genebra, Genebra.

MARINHO, J. H. C. 2002. O funcionamento discursivo do item "onde": uma abordagem modular. 2002. 305f. Tese (Doutorado em Linguística) - Faculdade de Letras, Universidade Federal de Minas Gerais, Belo Horizonte.

.2004. Uma abordagem modular e interacionista da organização do discurso. Revista da Anpoll 16. São Paulo. Jan/jun., p. 75-100.

. 2007. A determinação da unidade textual mínima. In: MARINHO, J. H.

C, PIRES, M. S. O.; VILLELA, A. M. N. (orgs.) Análise do discurso: ensaios sobre a complexidade discursiva. Belo Horizonte: CEFET-MG, p. 39-50.

, PIRES, M. S. O.; VILLELA, A. M. N. (orgs.) 2007. Análise do discurso: ensaios sobre a complexidade discursiva. Belo Horizonte: CEFET-MG, p. 39-50.

MATTHIESSEN, C; THOMPSON, S. 1988. The structure of discourse and 'subordination'. In: HAIMAN, J.; THOMPSON, S. (Eds.) Clause combining in Grammar and discourse. Amsterdam: John Benjamins Publishing, p. 275-329.

NEVES, M. H. M. 2002. A modalidade. In: KOCH, I. G. V. Gramática do português falado. v. 4: Desenvolvimentos. Campinas: Editora da Unicamp, p. 171-208.

RODRIGUES, R. H. 2005. Os gêneros do discurso na perspectiva dialógica da linguagem: a abordagem de Bakhtin. In: MEURER, J. L.; BONINI, A.; MOTTA-ROTH, D. (orgs.) Gêneros: teorias, métodos, debates. São Paulo: Parábola Editorial, p. 152-183.

ROULET, E. 2002. De la nécessité de distinguer des relations de discours sémantiques, textuelles et praxéologiques. In: ANDERSEN, H. L. \& NØLKE, H (eds.). Macro-syntaxe et macro-sémantique. Actes du Colloque International d'Aarhus. Bern: P. Lang.

ROULET, E. 2003. Une approche modulaire de la problematique des relations de discours. In: MARI, H. et al. Análise do discurso em perspectivas. Belo Horizonte: FALE/ UFMG, p. 149-178.

ROULET, E. 2006. The description of text relation markers in the Geneva model of discourse organization. In: FISCHER, K (ed.). Approaches to Discourse Particles. Amsterdam: Elsevier, p. 115-131.

ROULET, E.; FILLIETTAZ, L.; GROBET, A. 2001. Un modèle et un instrument d'analyse de l'organisation du discours. Berne: Lang. 
A articulação discursiva do gênero artigo de opinião à luz de um modelo modular de análise...

\title{
Discursive articulation of the Opinion article genre in the light of a modular model of discourse analysis
}

\begin{abstract}
This article aims to bring an understanding of how discourse construction functions in a specific genre, the opinion article. Based on the Model of Modular Discourse Analysis, we show that, in the attempt to convince the reader of a determined point of view, the author of an article employs various linguistic maneuvers, and reflected in the way that sections of the discourse are arranged hierarchically, with each section having different functions, such as functions of argument, development, commentary etc. To this end, we describe the relationships between the different parts of one specific article, addressing, initially, the way in which the author organizes the main sections of discourse, and secondly, how organization is arranged within these sections. The study allows us to verify that although the opinion article genre is monologic, the process of its production implies constant dialogue with the other, resulting in great complexity in its discursive organization.
\end{abstract}

Keywords: Discursive Articulation; Genre; Modularity; Opinion Article.

Recebido em: 05/11/2011

Aprovado em: 25/04/2012 